\title{
Mehdi Rahbar, Sajjad Alibaigi, Ernie Haerinck, Bruno Overlaet. «In Search of the Laodike Temple at Laodikeia in Media/Nahavand, Iran »
}

\section{Barbara Kaim}

\section{(2) OpenEdition}

Journals

Édition électronique

URL : http://journals.openedition.org/abstractairanica/45831

DOI : 10.4000/abstractairanica.45831

ISBN : 1961-960X

ISSN : 1961-960X

Éditeur :

CNRS (UMR 7528 Mondes iraniens et indiens), Éditions de l'IFRI

\section{Référence électronique}

Barbara Kaim, « Mehdi Rahbar, Sajjad Alibaigi, Ernie Haerinck, Bruno Overlaet. «In Search of the Laodike Temple at Laodikeia in Media/Nahavand, Iran » », Abstracta Iranica [En ligne], Volume 37-38-39 | 2018, document 27, mis en ligne le 30 décembre 2018, consulté le 27 septembre 2020 URL : http://journals.openedition.org/abstractairanica/45831; DOI : https://doi.org/10.4000/ abstractairanica.45831

Ce document a été généré automatiquement le 27 septembre 2020.

Tous droits réservés 


\title{
Mehdi Rahbar, Sajjad Alibaigi, Ernie Haerinck, Bruno Overlaet. «In Search of the Laodike Temple at Laodikeia in Media/Nahavand,
} Iran »

\author{
Barbara Kaim
}

\section{RÉFÉRENCE}

Mehdi Rahbar, Sajjad Alibaigi, Ernie Haerinck, Bruno Overlaet. « In Search of the Laodike Temple at Laodikeia in Media/Nahavand, Iran », IA 49, 2014, p. 301-329

1 L'identification de la ville de Nahavand avec l'ancienne Laodicée est assurée par le texte grec d'une stèle découverte par hasard en 1944 dans le quartier de Dokhaharan à Nahavand. L'inscription sur la stèle est une copie d'un édit d'Antiochos III concernant le culte dynastique à la reine Laodice, son épouse, envoyé sur tout le territoire de l'empire séleucide. Antiochos III ordonne au satrape de Médie Menedemos de construire un temple dédié à Laodice. Les $\mathrm{A}$. décrivent les résultats de deux saisons de fouilles archéologiques menées au nord-ouest de la ville de Nahavand. Des vestiges séleucides et parthes, tels que plusieurs bases de colonnes dispersées et souvent réutilisées, des fûts de colonnes et un chapiteau ionique suggèrent au moins un bâtiment de cette période situé dans cette partie de la ville, mais pour confirmer l'existence du temple de Laodice lui-même, il faudra attendre d'autres campagnes de fouilles. 


\section{AUTEURS}

\section{BARBARA KAIM}

Université de Varsovie 